\title{
Understanding How Students Use and Appreciate Online Resources in the Teaching Laboratory
}

\author{
http://dx.doi.org/10.3991/ijoe.v11i4.4562 \\ Sasha Nikolic \\ University of Wollongong, Australia
}

\begin{abstract}
The internet is a great resource student's use for learning. Reasons include the ease in searching with sites such as Google, or the vast collection of informative videos on YouTube. The teaching laboratory can also benefit from online resources, especially when students are deficient in prerequisite knowledge. The benefits are greatest when there are non-standard learning paths, and multiple entry points into a degree. This study undertakes a mixed methods research approach to try and understand how students use and appreciate an online resource, called the Training Laboratory, designed to support learning in the engineering teaching laboratory. The targeted resources are used to help support students as well as the laboratory teaching assistants (called laboratory demonstrators). The study finds that such resources are used by a substantial number of students to aid learning, increasing productivity, and improving teaching. The availability of such targeted resources leads to an improved student experience.
\end{abstract}

Index Terms - laboratory, online learning, teaching, training

\section{INTRODUCTION}

In engineering, the laboratory plays an important role in developing students' skills and knowledge [1-3]. The teaching laboratory can be a place to conduct physical experiments [4-6], learn via simulation [7-9], or experiment with real hardware in a virtual laboratory $[10,11]$. The teaching laboratories provide for learning in the cognitive, psychomotor, and affective domains [12] with the experience of using and understanding engineering equipment an asset for the student experience [1, 13]. Therefore, it is a benefit for engineering departments to provide a great laboratory learning experience.

Learning in the laboratory should be a scaffolded learning experience for optimum learning [14]. However, in modern times this may not be possible. In countries like Australia, education has changed from having almost all students follow a predictable, synchronous learning path from first year to fourth year, to having many students undertaking courses in a non-standard order. This is because students now have a range of entry paths and entry points for both domestic and international students. As a consequence, students are increasingly entering the degree with a different alignment of pre-requisite knowledge [15].

Differences in prerequisite knowledge are significantly noticeable in the engineering laboratory environment. Skills students gain in the laboratory includes the ability to design, construct, analyze, modify, plot, and observe [16]. Laboratory experiments are usually created with the understanding that students have already obtained a satisfactory level of pre-requisite knowledge in the use of various

\section{Theory Component:}

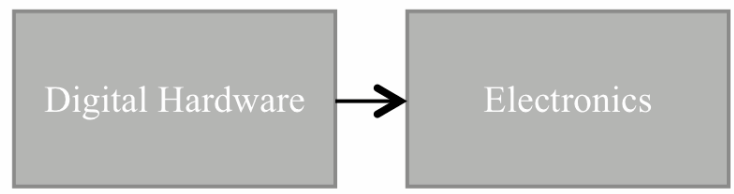

\section{Practical Component:}

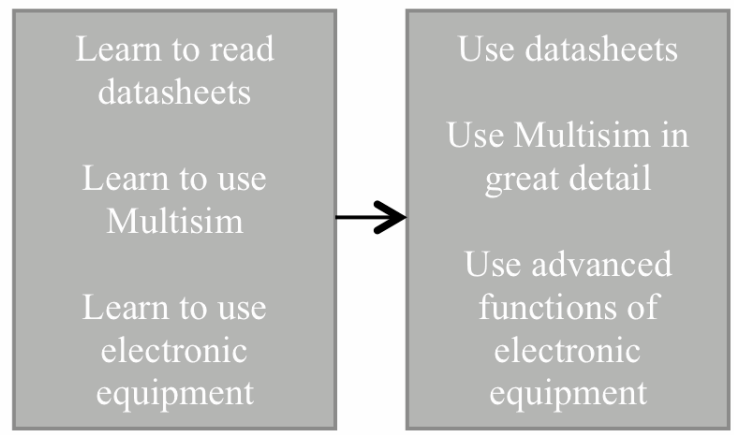

Figure 1. Example of a standard learning path, and the scaffolded learning in the laboratory

hardware and software. These presumptions, however, can cause significant stumbling blocks for students without these skills.

The design of a curriculum structure is generally based on the theory being taught. For example, in electrical engineering it does not matter if a course on the basics of digital hardware is taught before or after a course on the basics of electronics. However, if the laboratory component of one course introduces the basic principles and the other advances this knowledge, then the order in laboratory learning is important. For example, one course teaches the basics of understanding datasheets, simulation software, and using equipment, and the second course advances this knowledge to tackle more advanced experiments. For the laboratory component it would not be wise to do the second course before the first. An example of this is shown in Figure 1. Another scenario is when a student obtains advanced credit for the first course, based on the theoretical concepts, and goes straight into the second course. When it comes to the laboratory component, that student can unnecessarily struggle due to the lack of practical experience. This is especially evident with international students that may not have had the same level of access to laboratories.

The use of multimedia and online technologies provides the opportunity for sharing information [17], and can help bridge the gap with deficiencies in assumed knowledge 
[18]. It can also help cater for the difficult task of providing learning opportunities that reflect students' individual needs [19]. This includes the ease of searching with Google, or the millions of available videos on YouTube and other specialty sites. As examples, multimedia technology has been shown to improve the student learning experience in a telecommunications laboratory [14], a physics laboratory [20], across a range of courses [1], and it has also been shown as a valuable resource for teaching programming [21].

It is possible to develop a range of multimedia resources in-house in order to provide a custom solution. Developing in house online tools requires substantial time and effort [22]. Similarly, the design of laboratory notes can take a substantial amount of time, if the goal is to produce an experiment that meets student's satisfaction. One way to improve student experience is by providing a good introduction on how to use various software or hardware used in the laboratory [1]. This is usually carried out in the first and/or second experiment to develop fundamental understanding. In many instances the software and hardware may be used in multiple courses. Complications to the laboratory notes may occur when software or equipment is changed and laboratory notes need to be updated. This can take substantial workload if the resources are individualized across each course. These problems can be addressed by sharing resources across multiple courses.

In this paper, the way students use and appreciate an online resource called the Training Laboratory is investigated. This resource was designed and used in a School of Electrical, Computer and Telecommunications Engineering in an Australian university. Student interaction with the resource, benefits to laboratory teaching, and productivity gains are investigated.

\section{BACKGROUND AND MOTIVATION}

The purpose of this study is to understand how students use and appreciate an online resource in the laboratory, called the Training Laboratory. However, it is important to gain an insight into the design and usefulness of the resource.

\section{A. Teaching Assistants (Laboratory Demonstrator)}

The idea that sparked the development of the Training Laboratory was the need to improve the training delivered to teaching assistants used in the laboratory, called laboratory demonstrators [23]. Training teaching assistants is important to provide a quality learning experience for students, and this has resulted in many different training programs [23-26]. In the school, the overwhelming majority of teaching assistants are international PhD students. It was observed that the theoretical knowledge of the international students was very high, but lacking in terms of practical skills. This included knowledge on how to use the equipment in the laboratory, as well as an understanding of how to correctly troubleshoot problems. This problem needed to be rectified, because the laboratory is important for the development of psychomotor skills [12], and it was unacceptable to have demonstrators lacking these fundamental skills. As a result, a website was created that contained tutorial videos, text and picture information, and manuals that the laboratory demonstrators could use as preparation material.

\section{B. Pre-Requisite Student Knowledge}

The school is a popular destination for international students, making a large proportion of the student ratio in the third and fourth years. As many of the international students enter mid-way through the degree, a similar issue to the laboratory demonstrators presented itself. That is, the students were great at theory but the practical skills were not comparable with the students that started the degree in first year.

In Australia, multiple path ways are also causing a similar issue. Students can obtain advanced credit for courses from studies obtained from other universities or colleges [15]. In addition, the program structure for double degrees or other mixed programs can see students undertake courses in a nonstandard order. The resources developed in the Training Laboratory, provides the opportunity for students to catch up pre-requisite laboratory skills.

\section{Laboratory/Resource Design}

Designing laboratory experiments can take significant workload to be effective and increase student satisfaction. In particular developing video resources can be time consuming, but beneficial for learning [22]. The traditional method of developing laboratory notes is that the process is independent. Each course coordinator would individually (or course teaching team) go through the process of teaching and providing resources to complete the laboratory. A major drawback to this method is that productivity would be low, as it was common for different course coordinators to duplicate the creation of resources or instruction. A second problem existed if hardware or software changed, resulting in the need to update the resources. A third problem was it was often hard, to cater for students, that did not have the pre-requisite skills. Finally, advanced students could become bored, and lose interest in an experiment if it was too simple and repeated existing skills. It was best to share resources across courses, and to avoid repetitive learning by directing students to the online resource.

\section{The Internet}

A substantial amount of great resources is currently available on the internet that is free and useful in teaching skills used in the laboratory. With powerful search engines like Google, and extensive video resources on YouTube, students already have a number of pathways to teach themselves practical skills that may be deficient [27]. Finding information in this manner is a very important skill for engineers to have, and learning should always encourage this independent searching. There is however times when resources are wanted to be ad free, quick to navigate to, and delivered in a specific way.

\section{IMPLEMENTATION}

The Training Laboratory website was developed in 2011 and first used by students in 2012. Content is structured in four categories; Equipment, How to Guide (Hardware), How to Guide (Software), and Troubleshooting. The content includes written instructions, videos, user manuals and links to external resources. Over time, more resources have been developed or linked, to provide students a one stop shop to develop laboratory skills. The main page of the Training Laboratory can be seen in Figure 2 . 


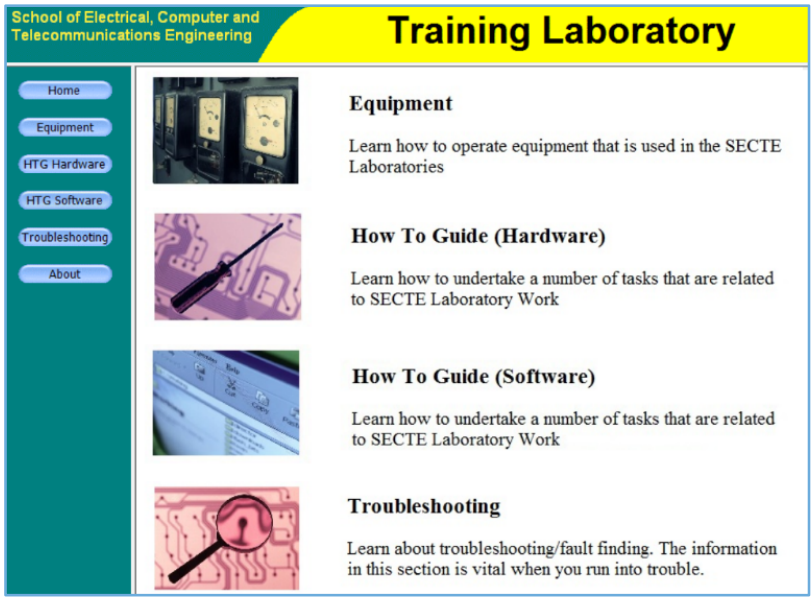

Figure 2. The Training Laboratory website

The development of each individual resource took a number of days, especially when creating video resources. It took time to develop a plan, undertake the recording, and then edit the video. If a company or website had a well-established training resource a link was provided to prevent unnecessary duplication.

The decision as to what resources where required, and how to design them, was determined by talking to experienced laboratory demonstrators and through observations in the laboratory environment. In particular, it was necessary to identify common student questions and the common mistakes made by students.

\section{RESEARCH DESIGN}

A study was conducted on three second year courses to try and understand how students used and perceived the Training Laboratory. The first course was on Digital Hardware (ECTE233) run in the first semester of the second year. The second course was on Electronics (ECTE212) run in the second semester of the second year of study. The digital hardware and electronics courses are undertaken by students studying computer, electrical, mechatronics, and telecommunications engineering. The third course investigated also ran in the second semester of second year. This was as an introductory electrical engineering servicing course for students studying other engineering degrees. This comprised of students studying civil, environmental, materials, mechanical and mining engineering.

In 2011, during the design of the resources for the Training Laboratory, a qualitative study was undertaken to observe students and laboratory demonstrators before implementation. The study looked at how the students interacted with the resources, experiments, each other and demonstrators. The Training Laboratory was added to ECTE233 and ECTE290 in 2012, and to ECTE212 in 2013. Observations were made again after implementation to see if the interactions changed.

In 2014 a quantitative study was undertaken to try and measure how usage changed over time, with the expectation that usage would reduce with each experiment in a course. This was conducted by a large course wide study in which students enrolled in ECTE233 filled in a survey at the end of the first, second and last experiments. The survey questions related to the Training Laboratory asked the question, "What was the main purpose of using the Training Laboratory?"

The second quantitative study was to investigate student use of the Training Laboratory across the three courses. At the end of the last experiment a survey was provided to students to gain an understanding on usage across various courses and how the resource impacted student satisfaction. The investigation also looked at how usage differed between local Australian students (Domestic Students), and foreign students (International Students) that had arrived to study for between one and four years of the bachelor degree in Australia. The survey questions related to the Training Laboratory asked the questions, "What was the main purpose of using the Training Laboratory?" and "If the resource was REMOVED how would your overall satisfaction for undertaking the experiments change?"

TABLE I.

RESPONSES FOR THE $1^{\text {ST }}, 2^{\text {ND }}$ AND $6^{\text {TH }}$ EXPERIMENTS TO THE QUESTION, “WHAT WAS THE MAIN PURPOSE OF USING THE TRAINING LABORATORY?”

\begin{tabular}{|l|c|c|c|}
\hline \multicolumn{1}{|c|}{ Answer Options } & First Experiment & Second Experiment & Last Experiment \\
\hline a) To learn how to use the equipment & $30.6 \%$ & $30.5 \%$ & $29.2 \%$ \\
\hline b) To learn how to troubleshoot & $2.0 \%$ & $11.9 \%$ & $6.2 \%$ \\
\hline Both a and b equally & $59.2 \%$ & $40.7 \%$ & $41.5 \%$ \\
\hline Other & $2.0 \%$ & $1.7 \%$ & $4.6 \%$ \\
\hline Did not use the resource & $6.1 \%$ & $15.3 \%$ & $18.5 \%$ \\
\hline Response $(N=100)$ & $49 \%$ & $59 \%$ & $65 \%$ \\
\hline
\end{tabular}

TABLE II.

RESPONSES AFTER THE LAST EXPERIMENT TO THE QUESTION, “WHAT WAS THE MAIN PURPOSE OF USING THE TRAINING LABORATORY?”

\begin{tabular}{|l|c|c|c|c|c|}
\cline { 2 - 5 } \multicolumn{1}{c|}{} & \multicolumn{2}{c|}{ Digital Hardware } & \multicolumn{2}{c|}{ Electronics } & Electrical (Servicing) \\
\hline \multirow{2}{*}{$\begin{array}{c}\text { Answer Options } \\
\text { Domestic } \\
\text { Students }\end{array}$} & $\begin{array}{c}\text { International } \\
\text { Students }\end{array}$ & $\begin{array}{c}\text { Domestic Stu- } \\
\text { dents }\end{array}$ & $\begin{array}{c}\text { International } \\
\text { Students }\end{array}$ & $\begin{array}{c}\text { Allents } \\
\text { (International response low - } \\
2 / 287)\end{array}$ \\
\hline a) To learn how to use the equipment & $25.9 \%$ & $45.5 \%$ & $46.1 \%$ & $22.2 \%$ & $42.9 \%$ \\
\hline b) To learn how to troubleshoot & $7.4 \%$ & $0.0 \%$ & $11.5 \%$ & $0.0 \%$ & $2.4 \%$ \\
\hline Both a and b equally & $38.9 \%$ & $54.6 \%$ & $30.8 \%$ & $55.6 \%$ & $50.0 \%$ \\
\hline Other & $5.6 \%$ & $0.0 \%$ & $0.0 \%$ & $0.0 \%$ & $0.0 \%$ \\
\hline Did not use the resource & $22.2 \%$ & $0.0 \%$ & $11.5 \%$ & $22.2 \%$ & $4.8 \%$ \\
\hline Response & $\mathbf{6 6 \% ( 5 4 / 8 1 )}$ & $\mathbf{5 8 \% ( 1 1 / 1 9 )}$ & $\mathbf{5 1 \% ( 2 6 / 5 1 )}$ & $\mathbf{4 7 \% ( 9 / 1 9 )}$ & $\mathbf{1 5 \% ( 4 2 / 2 8 7 )}$ \\
\hline
\end{tabular}




\section{RESUlts}

\section{A. Quantitative Analysis}

The first study was used to understand how much students used the Training Laboratory between the first experiment and the last experiment, with the expectation being that there would be a rapid decrease. Table I shows that there was indeed a substantial drop off in usage between the first $(6.1 \%)$ and second experiment $(15.3 \%)$, with further decline being minimal, with only $18.5 \%$ of students not using the resource by the last experiment.

The second quantitative study was to examine how students were using the resource across three different courses. Table II provides a summary of how the students claimed they used the resource across the three courses.

The data has been broken up between domestic and international students, except for ECTE290. Of the 42 responses only two were from international students, too small for any meaningful comparison. However, as this is a servicing course with the students having no previous exposure to an electrical laboratory, it was expected that the students would need substantial use of the resource.

The data shows that the resource is valuable for supporting learning in the laboratory, with usage above $75 \%$ across the three courses. The data confirms that students used the resource to gain an understanding of the equipment and on improving troubleshooting skills. The usage was greatest for ECTE290. This was expected as students had no previous experience in the electrical laboratory, with only five percent not using the resource.

Previous research has highlighted the importance of providing such resources in the laboratory environment to improve the student experience and learning [1, 14]. While the data in Table II provided evidence that students used the resource in the classroom, the data in Table III shows how such resources can affect student satisfaction.

In the three courses, students were asked how their satisfaction for the experiments would change if the resource was removed. For ECTE233 $47.7 \%$ of students claimed that their student satisfaction would reduce, while for ECTE212 and ECTE290 it was much larger being 65.7\% and $83.3 \%$ respectively. These figures are well correlated with the amount of resources a student might need to use from the Training Laboratory. This data also provides support to the claims made in $[1,14]$ that found online and multimedia resources in the laboratory can significantly improve the student experience and learning.

\section{B. Qualitative Analysis}

The students were observed before and after the Training Laboratory was incorporated into the laboratory notes for each course. Before implementation it was a regular occurrence for students to stop working when they had difficulty with the experiments. This was especially the case for early experiments and for international students. The international students in particular struggled to complete experiments, as they were coming into the laboratory not only having to understand the learning objectives, but also to try and understand how to use equipment that was foreign to them. It was observed that learning in the laboratory was not very effective for those new to the equipment. The laboratory demonstrators were also very busy trying to explain how the equipment worked, as well as provide help on the learning objectives of the experiment. This high workload resulted in many students waiting long periods to receive help. During these periods most were very unproductive.

Implementation of the Training Laboratory also required training for the laboratory demonstrators on how to use it effectively for teaching purposes. Observations were made in laboratory classes with demonstrators trained to use the resource as an aid to learning. If the laboratory demonstrators were asked a question that was covered in the Training Laboratory the first step was to point the students to the relevant resource. For example, consider the scenario where students are unaware of how to measure the current in a circuit with a digital multimeter. The laboratory demonstrator would show the students the relevant resources available, in regards to using the digital multimeter, and how to undertake electrical measurements. This was followed by asking the students if they had reviewed the information contained within the resource.

In most cases the students would not have explored the available resources, or if they had this would help them remember. The laboratory demonstrator would ask the students to review the resource, and that they would return in five minutes to check if they had gained the required level of understanding. This allowed the laboratory demonstrator more time to spend with the rest of the class, instead of investing a significant amount of time teaching the fundamental skills. Upon returning to the students, if the appropriate level of understanding had still not been reached, the laboratory demonstrator would identify the issue and help guide the students to the necessary level of understanding.

Using the process described, caused a significant increase in learning productivity. As student awareness grew of the resources, and they knew that the demonstrator would always start by pointing them to the resource, they began using it more when they ran into trouble. A direct result of this was that students were no longer sitting and waiting for help as much as they had previously done. The demonstrators were more flexible with the time they could share across all students. The time required to help students shortened, and this resulted in seeing more students more often.

TABLE III.

RESPONSES AFTER THE LAST EXPERIMENT TO THE QUESTION, “IF THE TRAINING LAB RESOURCE WAS REMOVED HOW WOULD YOUR OVERALL SATISFACTION FOR THE EXPERIMENTS CHANGE?"

\begin{tabular}{|c|c|c|c|}
\hline Answer Options & Digital Hardware & Electronics & Electrical (Servicing) \\
\hline Overall satisfaction would significantly improve & $1.5 \%$ & $0.0 \%$ & $0.0 \%$ \\
\hline Overall satisfaction would improve & $9.2 \%$ & $2.9 \%$ & $0.0 \%$ \\
\hline Overall satisfaction would NOT change & $32.3 \%$ & $25.7 \%$ & $16.7 \%$ \\
\hline Overall satisfaction would decrease & $40.0 \%$ & $45.7 \%$ & $57.1 \%$ \\
\hline Overall satisfaction would significantly decrease & $7.7 \%$ & $20.0 \%$ & $26.2 \%$ \\
\hline Undecided & $6.2 \%$ & $5.7 \%$ & $0.0 \%$ \\
\hline Response $(N=100, N=70, N=287)$ & $65 \%$ & $54 \%$ & $15 \%$ \\
\hline
\end{tabular}


As expected the Training Laboratory was of greatest benefit to international students that do not start in the first year of the undergraduate program (equal benefit in first year courses). A repeated observation, among a number of different laboratories, was that the resource provided the international students an opportunity to make better use of the laboratory time. Entering the laboratory for the first time was no longer a juggle between coming to terms with new foreign equipment/software, and concentrating on the learning objectives of the experiment.

Productivity in the laboratory was observed to be the best when the resources were tied to pre-laboratory activities. Differences in student preparation became noticeable. Students that used the resource were able to progress through the experiments at an increased pace, and resort to the troubleshooting resources without direction when needed. Students that made little use of the resource wasted time understanding the fundamentals and lacked direction when it came to troubleshooting. When these students struggled the tendency was to seek assistance from the demonstrator, rather than work out how to use resources to find a solution. It usually took the demonstrator a number of attempts to put the students into a routine, in order for them to seek out resources before asking for help.

\section{CONCLUSION}

This study aimed to investigate how students used an online resource called the Training Laboratory. The Training Laboratory contains easily accessible resources to help students understand laboratory equipment and troubleshooting techniques. Resources at the online site includes instruction manuals, instructional videos, written instructions and links to external resources. Students and laboratory demonstrators were observed in the laboratory before and after implementation. In 2014 a quantitative study was undertaken to understand how students used the resource and what relationship this had with the student experience. The results of the study supported the findings in $[1,14]$ that supportive online resources can have a large positive impact on student learning and the student experience. Students using such resources are more productive in the laboratory and are more focused on the learning objectives of the experiment. The resource is also most effective when laboratory demonstrators are trained to incorporate such resources when teaching.

\section{REFERENCES}

[1] S. Nikolic, C. Ritz, P. Vial, M. Ros, and D. Stirling, "Decoding Student Satisfaction: How to Manage and Improve the Laboratory Experience," IEEE Transactions on Education, vol. Online early access, 2014.

[2] T. Wolf, "Assessing Student Learning in a Virtual Laboratory Environment," IEEE Transactions on Education, vol. 53, pp. 216222, 2010. http://dx.doi.org/10.1109/TE.2008.2012114

[3] E. Lindsay and M. Good, "The impact of audiovisual feedback on the learning outcomes of a remote and virtual laboratory class," Education, IEEE Transactions on, vol. 52, pp. 491-502, 2009. http://dx.doi.org/10.1109/TE.2008.930510

[4] J. d. 1. H. i. Casas and A. d. B. del Hoyo, "'Learning by doing' methodology applied to the practical teaching of electrical machines," International Journal of Electrical Engineering Education, vol. 46, pp. 133-149, 2009. http://dx.doi.org/10.7227/IJEEE.46.2.2

[5] J. Dunne and B. Ryan, "Learning in the Science Lab: a New Approach," Irish Journal of Academic Practice, vol. 1, p. 18, 2012.
[6] J. Boxall and S. Tait. (2008, Inquiry-based learning in civil engineering laboratory classes. Proceedings of the ICE - Civil Engineering 161, 138-143.

[7] Z. Stanisavljevic, V. Pavlovic, B. Nikolic, and J. Djordjevic, "SDLDS - System for Digital Logic Design and Simulation," IEEE Transactions on Education, vol. 56, pp. 235-245, 2013. http://dx.doi.org/10.1109/TE.2012.2211598

[8] L. Yang-Mei and C. Bo, "Electronic Circuit Virtual Laboratory Based on LabVIEW and Multisim," in Intelligent Computation Technology and Automation (ICICTA), 2014 7th International Conference on, 2014, pp. 222-225. http://dx.doi.org/10.1109/ icicta.2014.61

[9] J. Djordjevic, B. Nikolic, and A. Milenkovic, "Flexible web-based educational system for teaching computer architecture and organization," Education, IEEE Transactions on, vol. 48, pp. 264-273, 2005. http://dx.doi.org/10.1109/TE.2004.842918

[10] D. Lowe, B. Dang, K. Daniel, S. Murray, and E. Lindsay, "On the viability of supporting institutional sharing of remote laboratory facilities," European Journal of Engineering Education, pp. 1-12, 2015. http://dx.doi.org/10.1080/03043797.2014.1001815

[11] N. Wang, X. Chen, G. Song, and H. Parsaei, "A Novel Real-time Video Transmission Approach for Remote Laboratory Development," International Journal of Online Engineering (iJOE), vol. 11, pp. pp. 4-9, 2015.

[12] K. R. Salim, A. Rosmah, N. H. HUSSAIN, and H. N. HARON, "An Instrument for Measuring the Learning Outcomes of Laboratory Work," presented at the International Engineering and Technology Education Conference, Ho Chi Minh City, Vietnam, 2013.

[13] A. C. Caminero, A. Robles-Gomez, S. Ros, L. Tobarra, R. Hernandez, R. Pastor, et al., "On the Creation of Customizable Laboratory Experiments: Deconstruction of Remote Laboratories to Create Laboratories as a Service (LaaS)," International Journal of Online Engineering (iJOE), vol. 10, pp. pp. 35-42, 2014.

[14] P. Vial, S. Nikolic, M. Ros, D. Stirling, and P. Doulai, "Using Online and Multimedia Resources to Enhance the Student Learning Experience in a Telecommunications Laboratory within an Australian University," Australasian Journal of Engineering Education, vol. 20, pp. 71-80, 2015.

[15] T. Millman, "Abridged Too Far? Credit Transfer: Examining the Transition Process from TAFE to University," Australian Journal of Adult Learning, vol. 53, pp. 326-335, 2013.

[16] I. E. Chika, D. Azzi, A. Hewitt, and J. Stocker, "A Holistic approach to assessing students' laboratory performance using Bayesian networks," in Computational Intelligence in Virtual Environments, 2009. CIVE '09. IEEE Workshop on, 2009, pp. 26-32.

[17] G. Sun and J. Shen, "Facilitating Social Collaboration in Mobile Cloud-Based Learning: A Teamwork as a Service (TaaS) Approach," IEEE Transactions on Learning Technologies, pp. 1-1, 2014.

[18] J. Wells, R. M. Barry, and A. Spence, "Using Video Tutorials as a Carrot-and-Stick Approach to Learning," IEEE Transactions on Education, vol. 55, pp. 453-458, 2012. http://dx.doi.org/10.1109/TE.2012.2187451

[19] E. Ambikairajah, V. Sethu, R. Eaton, and M. Sheng, "Evolving Use of Educational Technologies: Enhancing Lectures," Using Technology Tools to Innovate Assessment, Reporting, and Teaching Practices in Engineering Education, p. 241, 2014. http://dx.doi.org/10.4018/978-1-4666-5011-4.ch018

[20] R. A. Lewis, "Video introductions to undergraduate laboratories," University of Wollongong Teaching \& Learning Journal, vol. 2, pp. 33-37, 1994.

[21] S. Djenic, R. Krneta, and J. Mitic, "Blended Learning of Programming in the Internet Age," IEEE Transactions on Education, vol. 54, pp. 247-254, 2011. http://dx.doi.org/10.1109/ TE.2010.2050066

[22] G. S. Mason, T. R. Shuman, and K. E. Cook, "Comparing the Effectiveness of an Inverted Classroom to a Traditional Classroom in an Upper-Division Engineering Course," IEEE Transactions on Education, vol. 56, pp. 430-435, 2013. http://dx.doi.org/10.1109/ TE.2013.2249066

[23] S. Nikolic, P. Vial, M. Ros, D. Stirling, and C. Ritz, "Improving the Laboratory Experience: A Process to Train \& Manage Teaching Assistants," IEEE Transactions on Education, vol. Online early access, 2014. 
[24] C. Park, "The graduate teaching assistant (GTA): lessons from North American experience," Teaching in Higher Education, vol. 9, pp. 349-361, 2004. http://dx.doi.org/10.1080/13562510 42000216660

[25] E. Santhanam and G. Codner, "Enhancing undergraduate engineering education quality through teaching assistants (tutors/demonstrators)," Australasian Journal of Engineering Education, vol. 18, pp. 15-24, 2012. http://dx.doi.org/10.7158/D11132.2012.18.1

[26] R. Calvo, L. Markauskaite, and K. Trigwell, "Factors Affecting Students' Experiences and Satisfaction about Teaching Quality in Engineering," Australasian Journal of Engineering Education, vol. 16, pp. 139-148, 2010.
[27] D. Y. Lee and M. R. Lehto, "User acceptance of YouTube for procedural learning: An extension of the Technology Acceptance Model," Computers \& Education, vol. 61, pp. 193-208, 2// 2013.

\section{AUTHOR}

Sasha Nikolic is with University of Wollongong, Australia.

This article is an extended and modified version of a paper presented at the 2014 IEEE International Conference on Teaching, Assessment and Learning for Engineering (TALE2014), held 8-10 December, Te Papa Tongarewa National Museum of New Zealand, Wellington, New Zealand. Submitted 23 March 2015. Published as resubmitted by the author 25 June 2015. 